This is a post-print (i.e. final draft post-refereeing) copy of a manuscript submitted to the journal 'Skin Pharmacology and Physiology' (ISSN: 1660-5527, ESSN: 1660-5535)

Please cite as:

Zeka K, Ruparelia KC, Sansone C, Macchiarelli G, Continenza MA, Arroo RRJ (2018)

New Hydrogels Enriched with Antioxidants from Saffron Crocus Can Find Applications in Wound Treatment and/or Beautification. Skin Pharmacol Physiol. 31(2): 95-98.

doi: 10.1159/000486135. 


\title{
New Hydrogels Enriched with Antioxidants from Saffron Crocus Can Find Applications in Wound Treatment and/or Beautification
}

\author{
Keti Zeka ${ }^{\mathrm{a}, \mathrm{c}}$ Ketan C. Ruparelia ${ }^{\mathrm{b}, \mathrm{c}}$ ClaudiaSansone $^{\mathrm{a}}$ Guido Macchiarelli $^{\mathrm{a}}$ \\ Maria AdelaideContinenza ${ }^{a}$ Randolph R.J. Arroo ${ }^{b}$ \\ aDepartment of Life, Health and Environmental Sciences, University of L'Aquila, Italy; 'beicester School of Pharmacy, De \\ Montfort University, Leicester, United Kingdom. \\ ${ }^{\mathrm{c}}$ These authors contributed equally to the present work
}

\section{Keywords}

Crocus sativus L. · Drug delivery system · Kaempferol glycosides · Crocins · Hydrogel · Saffron

\begin{abstract}
Saffron extracts have a long history of application as skin protectant, possiblydue to their ability to scavenge free radicals. In this work, the performance of a hydrogel enriched with antioxidant compounds isolated from saffron crocus (CrocussativusL.) petals was tested. These hydrogels could be considered as new drug delivery system. Hydrogels are crosslinked polymer networks that absorb large quantities of water butretain the properties of a solid, thus making ideal dressings for sensitive skin. We tested antioxidant-enriched hydrogels on primary mouse fibroblasts. Hydrogels enriched with kaempferol and crocin extracted from saffron petals showed good biocompatibility with in vitro cultured fibroblasts. These newtypes of hydrogels may find applications in wound treatment and/or beautification.
\end{abstract}

\section{Introduction}

Since ancient times, saffron threads (the dried stigmas of the saffron crocus, Crocus sativus L.) have been widely used as a flavour enhancer in food, as a tonic, an appe- tizer, or as a digestive. Moreover, in the areas of its culti- vation, saffron has found applications in some medicinal preparations used to treatcolds, cardiovasculardisorders, and oculardisorders [1,2]. Currently, the petals of saffron flowers are discarded as waste material, though their chemical profile is similar to that of the stigmas [3]. It has been shown that saffron petals are rich in several antioxi- dant compounds like flavonols and flavanones [4], but contain less crocin [5]. The antioxidants have been con- sidered as the active ingredients responsible for a variety of health-enhancing properties that were traditionally at- tributed to saffron. This study focuses mainly on 2 anti- oxidant compounds, crocin and kaempferol, that are among the key natural antioxidants in the human 
diet, and are widely assumed to contribute to the health-en- hancing effect of fruits and vegetables [6-8]. Crocin, the main pigment of $C$. sativus stigmas, and the most abun- dant compound in saffron spice, has also been identified

Fig. 1. Mouse fibroblasts after 14 days of growth in the presence of hydrogel with hy- drogel without compounds (a, control), $2 \mathrm{mg} / \mathrm{mL}$ kaempferol (b), or $2 \mathrm{mg} / \mathrm{mL}$ cro- cin (c). The clear area is where the presence of the hydrogel formed a physical barrier that prevented cell invasion. All cells have a normal, healthy appearance.

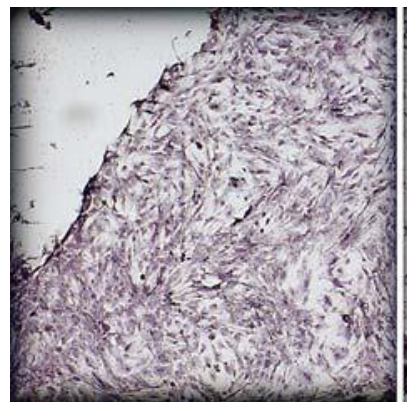

a

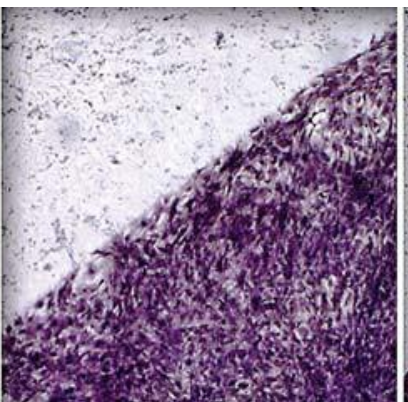

b

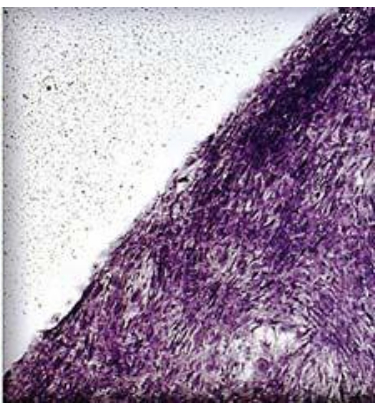

C

in petals of the saffron crocus $[9,10]$. Kaempferol and related flavonols, like quercetin, have received consider- able interest because of their antioxidant properties and their potential role in chemoprotection [11-13]. Kaemp- ferol is a well-studied flavonol and has been identified in a range of fruits and vegetables. Recently, petals of $C$. sa- tivus have been shown to be a particularly rich source of kaempferol glycosides [14, 15]. The total amount of gly- cosides in petal extracts was established by quantifying the amount of aglycone after hydrolysis. The amount of free kaempferol aglycone detectable before hydrolysis was negligible [16]. The aim of this study was to explore the potential of C. sativus petals as a possible source of antioxidants and chemopreventive compounds for use in hydrogels. These hydrogels could be considered an easy, cheap, enriched delivery system for applications either in treatment of difficult wounds or in wound healing masks and beauty masks as well $[13,17]$.

\section{Materials and Methods}

Hydrogels are structures capable of swelling and absorbing a large amount of water. They have the capacity to retain properties of a solid due to the presence of crosslinked networks between the macromolecular chains. Many naturally occurring polymers form hydrogels, e.g. poly-N68 acetylglucosamine in bacterial biofilms [18], hyaluronate in extracellular matrix components, agarose from seaweed, or glucomannans $[\beta-(1,4)$-acetylated mannan] from Aloe vera. Because of their outstanding capacity to retain at least $90 \%$ of water, hydrogels have been investigated for different biological purposes, e.g. delivery systems for drugs [19] and/or as improved dressing of wounds [20], 
and more recently in laser-as- sisted dental surgery [21]. In the present work, a hydrogel is composed by mixing an aqueous solution with 2 sets of biocompatible synthetic polymers, i.e. polyvinyl pyrrolidone and polyethylene glycol, and agar polysaccharide for jellification. The hydrogel was sterilized before use by gamma radiation at $25 \mathrm{kGy}$ [22]. Three separate solutions were prepared consisting of $60 \mathrm{~g}$ polyvinyl pyr- rolidone $+6 \mathrm{~g}$ agar $+12 \mathrm{~mL}$ polyethylene glycol 200 made up to a total volume of $600 \mathrm{~mL}$ with distilled water: i.e. the control solution contained just water, the 2 test solutions were made with water containing $160 \mathrm{mg} / \mathrm{L}$ of respectively kaempferol or crocin. The pu- rity of the compounds isolated from C. sativus flowers ranged from 96 to $98 \%$ as determined by HPLCDAD [23-25].

\section{Results}

The hydrogels all appeared clear and were colourless, yellow, and dark orange, respectively, for control, kaemp-ferol, and crocin. The objective of the in vitro test is to assess whether or not the biomaterial interface is toxic for mammalian cells. Since it is composed of a large quantity of water, the hydrogel is well tolerated by the skin. We chose fibroblasts (connective tissue cells) from newborn mice as a model for skin. This cell type grows readily in culture, and is best suited for changing environmental conditions, which is why it is most commonly used for experimental purposes [20]. The objective of the test is to estimate the cytotoxicity degree of a material for biomed-ical use, obtaining a rapid response as preliminary prepa- ration for future in vivo application [26]. Mice were sac- rificed with cervical dislocation. Fibroblasts were ob- tained by fragmenting the mouse connective tissue with sterile scissors and scalpel, finally digesting the tissue with trypsin. To prepare working solutions, $1.0 \mathrm{~mL}$ of trypsin (purchased in $2.5 \times$ concentrated) was mixed with $1.0 \mathrm{~mL}$ of foetal bovine serum. The isolated fibroblasts were grown, in Petri

dishes of 24 and $36 \mathrm{~cm}^{2}$, in Dulbecco's modified Eagle's medium supplemented with among others $10 \%$ $(\mathrm{v} / \mathrm{v})$ heat-inactivated foetal bovine serum, glutamine, and gentamycin. Cultures were maintained at $37^{\circ} \mathrm{C}$ in humidified air with $5 \% \mathrm{CO}_{2}$. At fixed deadlines, i.e. on the 3rd, 7th, and 14th days after reaching at least $80 \%$ cell confluence, all cultures were coloured using the Wright method for cell counting and other morphologi- cal evaluations. Figure 1 shows the results of the compat- ibility tests. From the microscopic images, supported by the cell density with the Image $\mathrm{J}$ programme, it can be seen that fibroblasts grow all the way up to the hydrogel, which presents a physical barrier that prevents invasion by the growing tissue. No cell-free zone of inhibition is observed, and no indications can be found for aberrant growth of cells (e.g. blebbing) in the immediate vicinity of any of the 3 hydrogels tested. Importantly, it was ob- served that cells grew faster in antioxidant-enriched hydrogels compared with the control.

\section{Discussion}

The US Food and Drug Administration (1946) lists 2 basic requirements to be met by a biomaterial to dispel any doubt on "biocompatibility": (a) security; (b) efficacy. The first requirement is satisfied by 
passing the test of di- rect cytotoxicity. While for the second requirement it is necessary to overcome a series of functionality tests de- signed to demonstrate the efficacy of the biomaterial implanted. The International Organization for Standardiza- tion and the American Society for Testing and Materials have published a series of guidelines outlining how mate- rial biocompatibility should be checked using in vitro tests oncellcultures. Only afterpassing the various assays established for this phase will materials be tested in vivo on laboratory animals, followed by clinical trials in humans. The main problem encountered in the preclinical applications of biomaterials relates to the verification of compatibility with the biological environment and is based on 3 main aspects:(1) morphological compatibility (aspect that concerns the size, shape and mass of the bio- material); (2) functional compatibility (aspect that con- cerns the role played by the material with respect to the expected role);(3) biocompatibility (takes care of the bio- material chemical and biological nature that can induce damaging alterations in relation to the biological sub- strate that is organ or tissue). We could speculate that our new type of enriched hydrogels is sufficiently flexible to adapt any type/shape of skin. With consideration of ste- rility, these hydrogels could potentially be used more eas- ily and with more efficacy than bandages as wound dress- ing for difficult wounds. The biocompatibility is a rather important requirement because a biomaterial must never be harmful to the body in which it is implanted. The target applications of the hydrogels tested in this work are wounds that are classified under the name of "difficult wounds" caused by burns, abrasions, and ulcerations [13, 17]. Also wounds due to vascular or endocrine (diabetes) disease and injury due to prolonged compression or forces cutting causing mechanical stress to the tissues and the constriction of blood vessels (bedsores). They could be nicely used for beautification.

The concentrations of crocin and kaempferol glyco- sides used in the hydrogels were sufficiently high $(>10 \mu \mathrm{M})$ to exert antioxidant activity and protect against the effects of reactive oxygen species.

\section{Conclusions}

We have shown that our hydrogels can be considered as delivery system for saffron-derived antioxidants in wound management. The cell growth of the enriched hy- drogels compared with the control (Fig. 1) clearly dem- onstrates the capacity of the compounds extracted from saffron petals to stimulate fibroblast expansion. Impor- tantly, these new types of hydrogels are easy to use and do not need complicated guidelines. This paves the way for applications such as wound treatment and wound healing correlated certainly with the cosmetic sector. As a matter of fact, worldwide the new treatments are becoming strongly sensitive to the patients well-being [23]. 


\section{Acknowledgements}

These studies were supported by grants from De Montfort University, UK, and the University of L'Aquila, Italy. The authors are grateful to Lamberto Formiconi and the local people of Na- velli village for their cooperation, and to the EPSRC UK National Mass Spectrometry Facility at Swansea University.

\section{Statement of Ethics}

Authors declare that these studies has been conform to Institutional standards.

\section{Disclosure Statement}

We wish to confirm that there are no known conflicts of inter- est associated with this publication and there has been no significant financial support for this work that could have influenced its outcome.

\section{References}

1. Joukar S, Ghasemipour-Afshar E, Sheibani M, Naghsh N, Bashiri A: Protective effects of saffron (Crocus sativus) against lethal ventric- ular arrhythmias induced by heart reperfusion in rat: a potential anti-arrhythmic agent. Pharm Biol 2013;51:836-843.

2. Ohno Y, Nakanishi T, Umigai N, Tsuruma K, Shimazawa M, Hara H: Oral administration of crocetin prevents inner retinal damage in- duced by $\mathrm{N}$-methyl-D-aspartate in mice. Eur $\mathrm{J}$ Pharmacol 2012;690:84-89.

3. Goli SAH, Mokhtari F, Rahimmalek M: Phe- nolic compounds and antioxidant activity from saffron (Crocus sativus L.) petal. J Agric Sci 2012;4:175-181.

4. Serrano-Díaz J, Estevan C, Ángel Sogorb M, Carmona M, Alonso G L, Vilanova E: Cytotoxic effect against 3T3 fibroblasts cells of saf- fron floral bio-residues extracts. Food Chem 2014;147:55-59.

5. Moraga AR, Ahrazem O, Rambla JL, Granell A, Gomez LG: Crocins with high levels of sug- ar conjugation contribute to the yellow co- lours of early-spring flowering crocus petals. PLoS One 2013;8:e71946.

6. Andarwulan N, Batari R, Sandrasari DA, Bol- ling B, Wijaya H: Flavonoid content and antioxidant activity of vegetables from Indonesia. Food Chem 2010;121:1231-1235.

7. Arroo RRJ, Beresford K, Bhambra AS, Board- er M, Budriesi R, Cheng Z, Micucci M, Ruparelia KC, Surichan S, Androutsopoulos VP: Phytoestrogens as natural prodrugs in cancer prevention: towards a mechanistic model. Phytochem Rev 2014;13:853-866. 
8. DuPont MS, Day AJ, Bennett RN, Mellon FA, Kroon PA: Absorption of kaempferol from endive, a source of kaempferol-3-glucuro- nide, in humans. Eur J Clin Nutr 2004;58: 947954.

9. Castillo R, Fernández JA, Gómez-Gómez L: Implications of carotenoid biosynthetic genes in apocarotenoid formation during the stig- ma development of Crocus sativus and its closer relatives. Plant Physiol 2005;139:674- 689.

10. Gutheil WG, Reed G, Ray A, Anant S, Dhar A: Crocetin: an agent derived from saffron for prevention and therapy for cancer. Curr Pharm Biotechnol 2012;13:173-179.

11. Hatahet T, Morille M, Hommoss A, Devois- selle JM, Müller RH, Bégu S: Quercetin topical application, from conventional dosage forms to nanodosage forms. Eur J Pharm Biopharm 2016;108:41-53.

12. Lee KM, Lee KW, Jung SK, Lee EJ, Heo YS, Bode AM, Lubet RA, Lee HJ, Dong Z: Kaempferol inhibits UVB-induced COX-2 expres- sion by suppressing Src kinase activity. Bio- chem Pharmacol 2010;80:2042-2049.

13. Majtan J, Bohova J, Garcia-Villalba R, Tomas- Barberan FA, Madakova Z, Majtan T, Majtan V, Klaudiny J: Fir honeydew honey flavonoids inhibit TNF- $\alpha$-induced MMP-9 expression in human keratinocytes: a new action of honey in wound healing. Arch Dermatol Res 2013; 305:619627.

14. Benayad Z, Gómez-Cordovés C, Es-Safi NE: Characterization of flavonoid glycosides from fenugreek (Trigonella foenum-graecum) crude seeds by HPLC-DAD-ESI/MS analysis. Int J Mol Sci 2014;15:20668-20685.

15. Montoro P, Maldini M, Luciani L, Tuberoso CIG, Congiu F, Pizza C: Radical scavenging activity and LC-MS metabolic profiling of petals, stamens, and flowers of Crocus sativus L. J Food Sci 2012;77:C893-C900.

16. Zeka K, Ruparelia KC, Continenza MA, Sta- gos D, Vegliò F, Arroo RRJ: Petals of Crocus sativus $\mathrm{L}$. as a potential source of the antioxi- dants crocin and kaempferol. Fitoterapia 2015;107:128-134.

17. Park SN, Kim SY, Lim GN, Jo NR, Lee MH: In vitro skin permeation and cellular protective effects of flavonoids isolated from Suaeda as- paragoides extracts. J Ind Eng Chem 2012;18: 680-683. 18. Kropec A, Maira-Litran T, Jefferson KK, Grout M, Cramton SE, Goldmann DA, Pier GB: Poly-N-acetylglucosamine production in Staphylococcus aureus is essential for viru- lence in murine models of systemic infection. Infect Immun 2005;10:6868-6876.

19. Singh S: Nanomedicine-nanoscale drugs and delivery systems. J Nanosci Nanotechnol 2010;10:7906-7918.

20. Zhang L, Li K, Xiao W, Zheng L, Xiao Y, Fan H: Preparation of collagen-chondroitin sul- fatehyaluronic acid hybrid hydrogel scaf- folds and cell compatibility in vitro. Carbo- hydr Polym $2011 ; 84: 118-125$. 
21. Bernardi S, Mummolo S, Zeka K, Pajewski L, Continenza MA, Marzo G: Use and evaluation of a cooling aid in laser-assisted dental surgery: an innovative study. Photomed Laser Surg 2016;34:258-262.

22. Rosiak JM, Rucinska-Rybus A, Pekala W: Method of manufacturing of hydrogel dress-ings; Polish patent No 151,581, US patent No 4,871,490, Hungarian patent No 204,866, UK patent No. 2,200,643, German patent No 3,744,289. 1989.

23. Goupy P, Abert Vian M, Chemat F, Caris- Veyrat C: Identification and quantification of flavonols, anthocyanins and lutein diesters in petals of Crocus sativus by ultra-performance liquid chromatography coupled to diode ar- ray and ion trap mass spectrometry detec- tions. Ind Crops Prod 2013;44:496-510.

24. Termentzi A, Kokkalou E: LC-DAD-MS (ESI+) analysis and antioxidant capacity of Crocus sativus petal extracts. Planta Med 2008;74:573-581.

25. Verrastro IS, Pasha KT, Pitt AR, Spicket CM: Mass spectrometry-based methods for identifying oxidized proteins in disease: advances and challenges. Biomolecules 2015; 5: 211 378-341.

26. Zou SB, Yoon WY, Han SK, Jeong SH, Cui ZJ, Kim WK: Cytotoxicity of silver dressings on diabetic fibroblasts. Int Wound J 2013;10: 306-312.

27. Grothier L, Pardoe A: Chronic wounds: man- agement of healing and wellbeing. Br J Nurs 2013;10;22:S24, S26-S33. 